\title{
Darolutamide: An Evidenced-Based Review of Its Efficacy and Safety in the Treatment of Prostate Cancer
}

This article was published in the following Dove Press journal: Cancer Management and Research

\section{E David Crawford' \\ Whitney Stanton (iD ${ }^{2}$ \\ Divneet Mandair ${ }^{2,3}$}

'Department of Urology, University of California at San Diego, La Jolla, CA, USA; ${ }^{2}$ Department of Pathology, University of Colorado School of Medicine, Aurora, CO, USA; ${ }^{3}$ Division of Internal Medicine, University of Colorado School of Medicine, Aurora, CO, USA
Correspondence: E David Crawford Email edc@edavidcrawford.com

\begin{abstract}
Men treated with androgen deprivation therapy for rising PSA after failed local therapy will often develop castrate resistance, and the appearance of metastases predicts a poor prognosis. Thus, researchers have long sought to prolong the onset of metastasis in patients with nonmetastatic castration-resistant prostate cancer (CRPC). Until 2018, patients in this group had no FDA-approved treatment options. They were typically managed with androgen-deprivation therapy (ADT) to maintain castrate systemic testosterone levels and given approved therapies for metastatic CRPC once metastases appeared. However, third-generation androgen receptor inhibitors (ARIs) have dramatically changed the treatment paradigm, having shown the ability to extend metastasis-free survival (MFS) significantly over ADT alone in Phase 3 trials. The newest of these, darolutamide, prolonged MFS 22 months over placebo while also improving a host of secondary and exploratory endpoints such as overall survival (OS), prostate-specific antigen (PSA) progression and time to pain progression, chemotherapy initiation, and symptomatic skeletal events. Among third-generation ARIs, darolutamide is unique in that it incorporates two pharmacologically active diastereomers and has demonstrated resistance to all known androgen receptor (AR) mutations. Additionally, patients taking darolutamide appear to experience comparatively few central nervous system-related adverse events (AEs) such as fatigue and falls, and no increases in seizures have been reported in the drug's clinical or preclinical development. Various authors attribute the low incidence of CNS-related AEs to darolutamide's minimal penetration of the blood-brain barrier (BBB). Other side effects ranging from hot flashes to hypothyroidism also occurred at rates similar to those of the placebo arm in Phase 3 . As ADT in itself raises cardiovascular risk, the cardiovascular safety of third-generation antiandrogens as a category warrants continued scrutiny. In total, however, published data suggest that darolutamide provides a reasonable option for patients with nonmetastatic CRPC. Ongoing research will determine darolutamide's potential role in additional disease states such as localized and castration-sensitive PCa.
\end{abstract}

Keywords: nonmetastatic castration-resistant prostate cancer, darolutamide, androgen receptor inhibitors, androgen deprivation therapy

\section{Introduction}

The objective of this review is to discuss the efficacy and safety of darolutamide in PCa, while also briefly addressing CRPC, androgen receptor dynamics, and the characteristics of darolutamide in the context of existing third-generation androgen receptor inhibitors (ARIs).

Until recently, no US Food and Drug Administration (FDA)-approved options for nonmetastatic castration-resistant prostate cancer (M0CRPC/nmCRPC) existed. 
That changed with the approvals of enzalutamide, apalutamide, and, most recently, darolutamide, based largely on significant improvements in metastasis-free survival (MFS) versus placebo. With highly similar efficacy profiles, these drugs' safety, cost, and ease of accessibility for patients may become increasingly important determinants of adoption as physicians attempt to match patients with the optimal therapies for their clinical situations, preferences, and lifestyles. The generally asymptomatic nature of M0CRPC furthermore demands that safety and quality of life (QOL) figure strongly in these calculations.

Approved by the FDA for M0CRPC in 2019, darolutamide appears to offer efficacy and safety in this population. In the Phase 3 ARAMIS study, the drug significantly improved all primary, secondary, and exploratory endpoints versus placebo. ${ }^{1}$

Additionally, while adverse events (AEs) such as fatigue, falls, fractures have been associated with previous third-generation ARIs, darolutamide may offer lower rates of some of these AEs. Darolutamide moreover has shown low penetration of the blood-brain barrier (BBB) in animal and healthy human studies, and no central nervous system (CNS) AEs, such as seizures, have been reported thus far. These characteristics may make it a valuable addition to the treatment armamentarium for M0CRPC/ nmCRPC.

PCa remains the most frequently diagnosed noncutaneous cancer in US men. This year, the American Cancer Society has predicted 191,930 new PCa cases and 33,330 PCa deaths. ${ }^{2}$ Treatment options for high-risk PCa aim to prolong life and preserve QOL. Various guidelines recommend androgen deprivation therapy (ADT) as a cornerstone of the standard of care-both as an adjuvant to radical therapy for localized disease, and for recurrence/prostatespecific antigen (PSA) relapse after primary treatment. ${ }^{3-5}$ Chemical ADT seeks to decrease testosterone production by the testes to levels produced by bilateral orchiectomy. ${ }^{6}$ In both metastatic and nonmetastatic CRPC, guidelines strongly recommend continuing ADT to maintain testosterone below $20 \mathrm{ng} / \mathrm{dL}$. $^{4,5,7}$

Although most prostate cancers initially respond to ADT, nearly all eventually progress to CRPC. ${ }^{4,8,9}$ A CRPC diagnosis requires two to three rising serum PSA concentrations from nadir and/or evidence of radiographic progression despite castrate levels of serum testosterone. ${ }^{10}$ The American Urological Association (AUA) guidelines ${ }^{7}$ define PSA-only recurrence as the Prostate Cancer Clinical Trials Working Group 2 did: PSA 2 ng/mL higher than nadir that must also be at least $25 \%$ over the nadir, confirmed by a second PSA test at least three weeks later, in the presence of castrate testosterone levels and no radiographic evidence of metastases. ${ }^{11}$

CRPC presents as either metastatic (mCRPC) or nonmetastatic (M0CRPC/nmCRPC). The latter designation applies when ADT leads to castration resistance, but conventional imaging detects no metastases except to lymph nodes below the aortic bifurcation. ${ }^{12,13}$ Some cases originally diagnosed as nonmetastatic using conventional imaging may be reclassified as metastatic when examined with more sensitive staging techniques such as 68 Gallium prostate-specific membrane antigen (PSMA)-11 positron emission tomography (PET)-computed tomography (CT). ${ }^{14}$

\section{Materials and Methods}

Using resources including PubMed, meeting abstracts, guidelines of care, and www.clinicaltrials.gov, the authors reviewed available medical literature through February 2020 for relevant Phase 3 trials, comprehensive reviews, and treatment guidelines. Search terms such as darolutamide, androgen deprivation therapy/ADT, antiandrogens, and nonmetastatic castrate resistant prostate cancer/M0CRPC/ nmCRPC yielded more than 100 publications, from which the most relevant were selected for inclusion in this review. Priority was given to clinical and preclinical trials of darolutamide reporting efficacy and safety outcomes, as well as to reviews that discussed third generation ARIs as a category. From the reference lists of such publications, authors selected supporting articles where needed.

\section{Results}

\section{Attacking Androgens}

During the past three decades, a highly nuanced understanding of AR biology has developed. ${ }^{15}$ In short, the testes and adrenal glands produce testosterone. Testosterone and dihydrotestosterone (DHT), the two main androgens responsible for prostate growth, bind to the AR. ${ }^{16}$ Five alpha reductase (5AR) converts testosterone to DHT, which has two to five times higher AR-binding affinity than does testosterone. ${ }^{17,18}$

Before activation, the AR resides in the cytoplasm, bound to chaperone proteins belonging to the heatshock family. When androgens bind to the AR, these chaperones are released, allowing the AR to homodimerize and translocate to the nucleus. There, it acts as a transcription factor for androgen-responsive genes such as PSA and others. ${ }^{15}$ 
Many stages of the AR signaling process allow for therapeutic targeting, such as sequestering DHT ligands that activate the AR, blocking AR N-C terminal interaction, disrupting AR co-activator interaction, and preventing AR nuclear translocation. ${ }^{19,20}$ The 1950 s and early 1960 s saw the arrival of steroidal antiandrogens including cyproterone acetate (CPA), megestrol acetate, and medroxyprogesterone acetate. CPA monotherapy can provide total androgen blockade and may be used to suppress hot flushes associated with orchiectomy or gonadotropin-releasing hormone (GnRH) agonist therapy. ${ }^{21}$ However, its use has been largely discontinued due to concerns including poor efficacy (as monotherapy or in combination with surgical castration) $)^{22,23}$ and hepatotoxicity. ${ }^{24}$ Steroidal antiandrogens also may exert many off-target effects including impotence and decreased libido ${ }^{25}$ and have given way to more selective antiandrogens.

\section{First- and Second-Generation Nonsteroidal Antiandrogens}

The first nonsteroidal analogues used to block AR ligand activation in $\mathrm{PCa}$ include flutamide and nilutamide. Generally administered with medical or surgical castration, these agents were essentially indicated for neutralizing androgens from multiple sources, primarily the adrenal glands and cancers, a strategy known as combined androgen blockade (CAB). In pivotal studies of castration plus flutamide, nilutamide, or placebo, flutamide enzalutamide increased overall survival (OS) an average of 3 to 6 months. ${ }^{10}$ With efficacy similar to that of flutamide and nilutamide, the secondgeneration nonsteroidal antiandrogen bicalutamide was FDAapproved for PCa in 1995.

While flutamide, nilutamide and bicalutamide offered improvements over steroidal antiandrogens, all three earlier-generation nonsteroidal antiandrogens have been associated with the risk of both liver and gastrointestinal toxicities. ${ }^{10}$ Moreover, their relatively low affinity for the AR leaves an estimated 5-10\% of DHT free to stimulate the AR and continued PCa growth. ${ }^{26}$ Additionally, resistance to these agents develops rather quickly. ${ }^{27}$ In the context of excess AR, which aggressive PCa commonly produces, first- and second-generation nonsteroidal AR antagonists undergo a mechanistic switch to agonists, promoting tumor progression in preclinical models. ${ }^{28}$ Flutamide, nilutamide, and bicalutamide furthermore are almost completely susceptible to AR mutations, ${ }^{29}$ and with bicalutamide in particular, discontinuation leads to androgen withdrawal syndrome, in which tumors regress due to AR mutations and bicalutamide agonist activity. ${ }^{29}$

\section{Third Generation: AR Blockade}

As opposed to blocking AR ligand activation, sequestering the AR itself - which prevents nuclear translocation and subsequent signaling to AR target genes-represents the most commonly used form of antiandrogen therapy (see Figure 1). ${ }^{15}$ Third-generation ARIs share the same therapeutic goals as their predecessors while avoiding shortcomings including the antagonist/antagonist switch and androgen withdrawal syndrome. Third-generation ARIs also reduce toxicities through more targeted activity.

Enzalutamide inhibits AR nuclear translocation, recruitment of AR cofactors, and AR binding to DNA. ${ }^{30}$ With five- to eight-fold higher AR-binding affinity than bicalutamide, enzalutamide has demonstrated superiority to placebo when combined with castration in MOCRPC. ${ }^{31}$ The next third-generation ARI, apalutamide, offers similar in vitro activity to that of enzalutamide, but greater in vivo activity in xenograft models. ${ }^{30}$ In Phase 3 M0CRPC trials, enzalutamide and apalutamide achieved significant improvements over placebo in MFS and other endpoints. These drugs earned FDA approval for M0CRPC in 2018 based on Phase 3 results. ${ }^{31,32}$

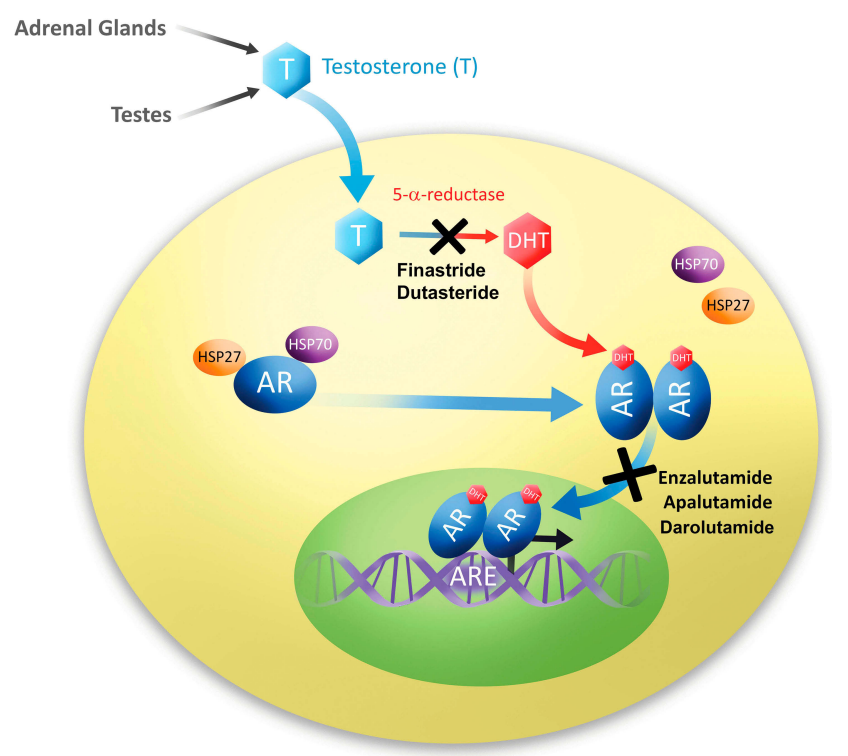

Figure I Proposed mechanisms of commonly used antiandrogens. ${ }^{15}$ Adapted from figure as originally published in Rice MA, Malhotra SV, Stoyanova T., Secondgeneration antiandrogens: from discovery to standard of care in castration resistant prostate cancer. Front Oncol. 2019;9:801. Available from: https://www.frontiersin. org/articles/I0.3389/fonc.2019.0080I/full. Accessed January 30, 2020. Adapted with permission. 


\section{Darolutamide}

Called ODM-201 during development, darolutamide is a synthetic compound discovered by screening campaign that used an AR transactivation assay in AR-HEK293 cells. ${ }^{33}$ Darolutamide's proposed mechanism of action is shown in Figure 1.

Darolutamide offers a unique molecular structure, incorporating a 1:1 mixture of two pharmacologically active diastereomers- $[\mathrm{S}, \mathrm{R}]$-darolutamide and $[\mathrm{S}, \mathrm{S}]$ darolutamide-which interconvert through the active major metabolite keto-darolutamide. ${ }^{33,34}$ In preclinical development, darolutamide and keto-darolutamide inhibited testosterone-induced AR translocation to the nucleus. ${ }^{33}$ Compared to enzalutamide and apalutamide, darolutamide and keto-darolutamide also demonstrated tighter AR bonding, stronger suppression of androgeninduced cell growth in vertebral metastatic cells ( $\mathrm{VCaP})$, and imperviousness to all known AR mutations shown to enable resistance to first- and second-generation ADTs. ${ }^{33}$ Additionally, oral darolutamide $(50 \mathrm{mg} / \mathrm{kg})$ once or twice daily provided antitumor activity in $\mathrm{VCaP}$ tumor-bearing mice. In a related experiment, enzalutamide-induced CNS stimulation significantly increased serum testosterone levels; darolutamide did not.

Mouse studies moreover showed low brain-plasma ratios of darolutamide and keto-darolutamide after seven days' oral dosing (1.9-3.9\% and $1.9-2.8 \%$, respectively) versus enzalutamide (27\%) and apalutamide (62\%). ${ }^{33}$ Quantitative whole-body autoradiography in rats supports the foregoing findings. Eight hours post-dosing, darolutamide was nearly undetectable in all tissues, including the brain, whereas enzalutamide remained constant and had a blood/brain ratio of approximately $0.765 .{ }^{35}$ Subsequent research with apalutamide showed that high brain concentrations (although twofold lower than those of enzalutamide) persisted for up to eight hours. Conversely, darolutamide brain concentrations were near the lower limit of quantification, approximately 26 and 46 times lower than levels of apalutamide and enzalutamide, respectively. ${ }^{36}$

\section{Darolutamide Phase I and 2}

In the Phase 1/2 ARADES trial in progressive mCRPC, darolutamide had a median time to maximum plasma concentration (Cmax) of 3.0 to 5.01 hours and a mean half-life of 15.8 hours (at steady-state) independent of dose. ${ }^{37}$ Because area under the curve (AUC) and $\mathrm{C}_{\max }$ values were approximately two times higher, and $\mathrm{C}_{\max }$ was delayed by two to three hours after a high-fat meal versus fasting, ${ }^{38}$ subsequent trials required that darolutamide be taken with food.

In the dose-escalation portion of ARADES, all six darolutamide doses tested (between 200 and $1800 \mathrm{mg}$ /day) showed antitumor activity at week 12 , and $81 \%$ of patients achieved $\geq 50 \%$ serum PSA reductions. No dose-limiting toxicities were reported. The Phase 2 portion included 12 patients from Phase 1 and an additional 110 who were randomized to darolutamide 200, 400, or $1400 \mathrm{mg} /$ day. At week 12, the proportions of patients who achieved $\geq 50 \%$ serum PSA reductions were $29 \%, 33 \%$, and $33 \%$ respectively. Compared to patients previously treated with cytochrome p450 enzyme 17R hydroxylase-1720-lyase (CYP17) inhibitors, there was a trend toward higher responses in patients naïve to both chemotherapy and CYP17 inhibitors (50-86\% PSA response rates, depending on dose), and those who had previously received chemotherapy but were CYP17-inhibitor-naïve. Additionally, the Phase 1 ARAFOR trial of darolutamide $1200 \mathrm{mg}$ /day in chemotherapy-naïve and CYP17-inhibitor-naïve mCRPC showed an $83 \%$ PSA response at week $12 .{ }^{39}$

Safety data from these trials showed that darolutamide was well tolerated. In ARADES, the most common AEs (all grades) were fatigue or asthenia (31\%), back pain $(21 \%)$, arthralgia (15\%), and pain (15\%); nearly all were mild or moderate. AEs considered to be treatment-related impacted $35 \%$ of patients. In ARAFOR, the most common AEs were fatigue and nausea, each affecting $13 \%$ of patients.

\section{Darolutamide Phase 3}

In the 16-week ARAMIS trial, Fizazi et al randomized 554 patients to placebo and 955 to darolutamide $600 \mathrm{mg}$ twice daily while continuing ADT. Patients were required to have CRPC, baseline PSA $\geq 2 \mathrm{ng} / \mathrm{mL}$, PSADT $\leq 10$ months, and an Eastern Cooperative Oncology Group (ECOG) performance status of 0 or 1 . Median MFS in the darolutamide cohort was 40.4 months, versus 18.4 months for placebo (Table 1), ${ }^{1}$ consistent with the performance of previous third-generation ARIs. The hazard ratio (HR) for metastasis or death in ARAMIS' darolutamide group was 0.41 (95\%) confidence interval/CI: $0.34-0.50 ; \mathrm{P}<0.001$.

Darolutamide was associated with a greater benefit in all secondary and exploratory ARAMIS endpoints versus placebo (Table 2). In interim OS analysis after 136 deaths, including 78 in the darolutamide group, the drug's HR of death versus placebo was 0.71 (95\%) CI: $0.50-0.99 ; \mathrm{P}=0.045$. Results from the preplanned final OS analysis of ARAMIS show a significant OS improvement in patients receiving 
Table I Phase 3 Efficacy of MOCRPC Drugs

\begin{tabular}{|l|l|l|l|}
\hline Drug (Trial) & Darolutamide (ARAMIS) & Enzalutamide (PROSPER) & Apalutamide (SPARTAN) \\
\hline Sample Size (total) & 1509 & $140 \mathrm{I}$ & 1207 \\
Median MFS (months, drug, vs placebo) & 40.4 vs I8.4(P<0.00I) & 36.6 vs I4.7 $(P<0.00 \mathrm{I})$ & 40.5 vs $16.2(P<0.00 \mathrm{I})$ \\
Median time to PSA progression & 33.2 vs $7.3(P<0.00 \mathrm{I})$ & 37.2 vs $3.9(P<0.00 \mathrm{I})$ & NR vs 3.7 \\
\hline
\end{tabular}

Table 2 Prespecified Secondary and Exploratory Efficacy Endpoints (ITT Population) Darolutamide $(n=955)$ Placebo $(n=554)$

\begin{tabular}{|c|c|c|c|c|c|c|}
\hline Endpoint & $\begin{array}{l}\text { Median } \\
\text { Duration (mos) }\end{array}$ & \# of Events & $\begin{array}{l}\text { Median } \\
\text { Duration (mos) }\end{array}$ & \# of Events & HR & $P$-value \\
\hline \multicolumn{7}{|l|}{ Secondary } \\
\hline - OS & NR & 78 & NR & 58 & 0.71 & 0.045 \\
\hline - TT pain progression & 40.3 & 251 & 25.4 & 178 & 0.65 & $<0.001$ \\
\hline - TT cylotoxic chemotherapy & NR & 73 & 38.2 & 79 & 0.43 & $<0.001$ \\
\hline - TT I I st $_{\text {symptomatic skeletal event }}$ & NR & 16 & NR & 18 & 0.43 & 0.01 \\
\hline PFS & 36.8 & 255 & 14.8 & 258 & 0.38 & $<0.001$ \\
\hline PSA progression & 33.2 & 226 & 7.3 & 368 & 0.13 & $<0.001$ \\
\hline $\mathrm{I}^{\text {st }} \mathrm{PCa}$-related invasive procedure & NR & 34 & NR & 44 & 0.39 & $<0.001$ \\
\hline Initiation of subsequent antineoplastic therapy & NR & 48 & NR & 70 & 0.33 & $<0.001$ \\
\hline
\end{tabular}

Note: From Fizazi K, Shore N, Tammela TL, et al. Darolutamide in nonmetastatic, castration-resistant prostate cancer. N Engl J Med. 2019;380(I3): I235-1246. Copyright (C) (2019) Massachusetts Medical Society. Reprinted with permission from Massachusetts Medical Society.'

darolutamide plus ADT versus placebo plus ADT $(\mathrm{HR}=0.69$, 95\% CI 0.53-0.88; $\mathrm{P}=0.003) .{ }^{40}$ Among patients who required additional antineoplastic therapy, the proportions in the darolutamide and placebo groups who received approved therapy for mCRPC were $29.5 \%$ and $36.7 \%$ respectively.

\section{Safety}

AE incidence in ARAMIS was generally similar between darolutamide and placebo (Tables 3 and 4). Except for fatigue, AEs that occurred or worsened during treatment and had a frequency of $\geq 5 \%$ impacted less than $10 \%$ of patients in either group. Of note, seizure incidence was $0.2 \%$ in both the darolutamide and placebo groups. Incidence of other AEs of interest, including hypertension, cognitive disorders, dizziness, and rash, varied only slightly between study arms, and the differences decreased or disappeared after adjustment for treatment duration or observation period. While cross-trial comparisons are subject to limitations (such as differences in patient populations, trial conduct, and others), overall Phase 3 rates of AEs and serious AEs were fairly consistent between darolumatide, enzalutamide, and apalutamide (Table 3). ${ }^{41}$

Table 4 shows respective rates of fatigue, falls, fractures, rashes, and other AEs commonly associated with third-generation antiandrogens vs placebo in these drugs' Phase 3 trials.

\section{Discussion}

Third-generation ARIs have risen to represent the standard of care in nonmetastatic CRPC. ${ }^{3,4,7}$ Darolumatide provides a valuable addition to the therapeutic armamentarium for several reasons. In Phase 3, the drug met all primary endpoints and reduced the risk of metastases or death from any cause by $59 \%$ consistently in all subgroups. While it is impossible to compare results directly across the studies (Table 1-6), it appears that key AEs that have been associated with prior third-generation ARIs occur at similar rates with darolutamide.

Along with disease progression, treatment-associated AEs can decrease health-related QOL. ${ }^{42}$ ARAMIS authors Fizazi et al observe that because patients with nmCRPC may already be suffering adverse effects from their ongoing ADT, they can ill afford additional toxic effects associated with their choice of MOCRPC therapy. ${ }^{1}$

With virtually identical Phase 3 efficacy levels for apalutamide, enzalutamide, and darolutamide, these drugs' safety and QOL profiles will be important to guiding their use, particularly as most men with M0CRPC are asymptomatic when they begin treatment. ${ }^{12,16}$

\section{CNS-Related AEs Including Seizures}

Compared to earlier-generation AAs, the main new side effect associated with enzalutamide and apalutamide is 
Table 3 Phase 3 Adverse Events

\begin{tabular}{|l|l|l|l|}
\hline Drug & $\begin{array}{l}\text { Any AE } \\
\text { (Drug vs } \\
\text { Placebo) }\end{array}$ & $\begin{array}{l}\text { Severe AEs } \\
\text { (Grade } \geq 3 ; \\
\text { Drug vs } \\
\text { Placebo) }\end{array}$ & $\begin{array}{l}\text { AEs Leading to } \\
\text { Drug } \\
\text { Discontinuation } \\
\text { (Drug vs Placebo) }\end{array}$ \\
\hline $\begin{array}{l}\text { Darolutamide } \\
\text { Enzalutamide } \\
\text { Apalutamide }\end{array}$ & $\begin{array}{l}83.2 \% \text { vs } 76.9 \% \\
86.5 \% \text { vs } 77 \%\end{array}$ & $\begin{array}{l}24.7 \% \text { vs } 19.5 \% \\
31 \% \text { vs } 23 \%\end{array}$ & $\begin{array}{l}8.9 \% \text { vs } 8.7 \% \\
9 \% \text { vs } 6 \% \\
10.7 \% \text { vs } 23.1 \%\end{array}$ \\
\hline
\end{tabular}

increased risk of seizure, due to penetration of these compounds through the BBB and subsequent inhibition of the y-aminobutyric acid receptor $\left.\left(\mathrm{GABA}_{\mathrm{A}}\right)\right)^{1,15}$ Nevertheless, rates of seizures in Phase 3 trials of enzalutamide and apalutamide were low and did not reach statistical significance. Also in these trials, CNS-related AEs such as fatigue, mental impairment disorders, and dizziness also occurred more often among patients receiving these drugs than placebo. ${ }^{31,32}$ Such AEs can negatively impact QOL, particularly in elderly patients who are more prone to falls and cognitive impairment such as dementia. ${ }^{43}$ Seizures were also noted as a potential risk in Phase 1 and 2 studies of enzalutamide. ${ }^{44}$

Darolutamide has shown low BBB penetration, and this may be associated with preclinical and clinical data that show low proconvulsive potential. ${ }^{45}$ Unlike in Phase 3 trials of enzalutamide and apalutamide, patients with a history of seizures or predisposing conditions were permitted to enroll in ARAMIS. During ARAMIS, no patients with a history of seizure (there were 12 in the darolumatide group) experienced a seizure. ${ }^{1}$ Fizazi et al also attribute the similar incidences of dizziness and cognitive impairment in the
ARAMIS darolumatide and placebo groups to the low BBB penetration discovered in preclinical darolumatide studies. ${ }^{1}$

\section{Cardiovascular AEs}

Meta-analyses show significant associations between use of third-generation ARIs and fatigue, fractures, falls, hypertension, and cardiovascular events. ${ }^{46,47}$ These drugs' combined relative risk (RR) of grade $\geq 3$ hypertension, for example, is 1.39. ${ }^{46,47}$ Individual Phase 3 RRs of Grade $\geq 3$ hypertension for darolumatide, enzalutamide, and apalutamide, respectively, were $1.452,2.150$, and $1.213 .^{47}$ Moreover, Di Nunno et al link the category as a whole with significantly increased risk of AE-related death, although these authors note that no AE-related deaths occurred in ARAMIS. ${ }^{47}$

The cardiovascular and cerebrovascular safety of nextgeneration antiandrogens warrants continued scrutiny, as background ADT is already known to elevate cardiac risk. ${ }^{48,49}$ Abiraterone acetate (AA) is no exception. While enzalutamide, apalutamide, and darolutamide block the AR, AA inhibits CYP17AI, which is involved in testosterone biosynthesis. ${ }^{15,50,51} \mathrm{AA}$ remains the only androgen biosynthesis inhibitor approved by the FDA for PCa. There is, however, no phase 3 trial of AA in MOCRPC, only promising results from the Phase 2 IMAAGEN trial. ${ }^{12,52}$

In Phase 3 trials for mCRPC, cardiac disorders occurred at slightly higher rates with abiraterone than placebo $(19 \% /$ $13 \%$ abiraterone vs $16 \% / 11 \%$ placebo). ${ }^{53,54}$ Additionally, a meta-analysis of seven studies (two in HSPC, five in CRPC) revealed statistically significant risks of all-grade (RR 1.41) and high-grade (2.22) cardiac toxicity and arterial

Table 4 Phase 3 Specific Adverse Events 1,|2,31,32,41

\begin{tabular}{|l|l|l|l|}
\hline AEs (Any Grade) & Darolutamide vs Placebo & Enzalutamide vs Placebo & Apalutamide vs Placebo \\
\hline Fatigue or asthenic conditions & $15.8 \%$ vs $11.4 \%$ & $33.0 \%$ vs $14.0 \%$ & $30.4 \%$ vs $21.1 \%$ \\
Fractures & $4.2 \%$ vs $3.6 \%$ & NR & $11.7 \%$ vs $6.5 \%$ \\
Falls & $4.2 \%$ vs $4.7 \%$ & $11.0 \%$ vs $4.0 \%$ & $15.6 \%$ vs $9.0 \%$ \\
Dizziness & $4.5 \%$ vs $4.0 \%$ & $10 \%$ vs $4 \%$ & $9.3 \%$ vs $6.3 \%$ \\
Seizures & $0.2 \%$ vs $0.2 \%$ & $<1 \%$ vs 0 & $0.2 \%$ vs 0 \\
Mental impairment/cognitive disorder & $0.4 \%$ vs $0.2 \%$ & $5.0 \%$ vs $2.0 \%$ & $5.1 \%$ vs $3.0 \%$ \\
Memory impairment & $0.5 \%$ vs $1.3 \%$ & NR & NR \\
Hypertension & $6.6 \%$ vs $5.2 \%$ & $12.0 \%$ vs $5.0 \%$ & $24.8 \%$ vs $19.8 \%$ \\
Hypothyroidism & $0.2 \%$ vs 0 & $\mathrm{NR}$ & $8.1 \%$ vs $2.0 \%$ \\
Hot flashes & $5.2 \%$ vs $4.2 \%$ & $13 \%$ vs $8 \%$ & $\mathrm{NR}$ \\
Rash & $2.9 \%$ vs $0.9 \%$ & $\mathrm{NR}$ & $23.8 \%$ vs $5.5 \%$ \\
Diarrhea & $6.9 \%$ vs $5.6 \%$ & $10.0 \%$ vs $10.0 \%$ & $20.3 \%$ vs $15.1 \%$ \\
Weight loss & $3.6 \%$ vs $2.2 \%$ & $6.0 \%$ vs $2 \%$ & $16.1 \%$ vs $6.3 \%$ \\
Nausea & $5.0 \%$ vs $5.8 \%$ & $11 \%$ vs $9 \%$ & $18.1 \%$ vs $15.8 \%$ \\
Arthralgia & $8.1 \%$ vs $9.2 \%$ & $8 \%$ vs $7 \%$ & $15.9 \%$ vs $7.5 \%$ \\
\hline
\end{tabular}


Table 5 Cerebrovascular Events in ARAMIS

\begin{tabular}{|l|l|l|l|l|l|l|}
\hline AE & $\begin{array}{l}\text { Darolutamide } \\
\text { Any Grade }\end{array}$ & $\begin{array}{l}\text { Darolutamide } \\
\text { Grade 3 or 4 }\end{array}$ & $\begin{array}{l}\text { Darolutamide } \\
\text { Grade 5 }\end{array}$ & $\begin{array}{l}\text { Placebo Any } \\
\text { Grade }\end{array}$ & $\begin{array}{l}\text { Placebo } \\
\text { Grade 3 or 4 }\end{array}$ & $\begin{array}{l}\text { Placebo } \\
\text { Grade 5 }\end{array}$ \\
\hline Cerebral ischemia & $13(1.4 \%)$ & $7(0.7 \%)$ & $1(0.1 \%)$ & $8(1.4 \%)$ & $4(0.7 \%)$ & $3(0.5 \%)$ \\
Coronary artery disorder & $31(3.2 \%)$ & $16(1.7 \%)$ & $3(0.31 \%)$ & $14(2.5 \%)$ & $2(0.4 \%)$ & $1(0.1 \%)$ \\
Heart failure & $18(1.9 \%)$ & $5(0.5 \%)$ & $4(0.4 \%)$ & $5(0.9 \%)$ & 0 & $3(0.5 \%)$ \\
\hline
\end{tabular}

Table 6 Ongoing Trials in Additional PCa Settings

\begin{tabular}{|c|c|c|c|c|c|c|}
\hline Study & Setting & Phase & Study Arms & $\begin{array}{l}\text { Primary } \\
\text { Endpoint }\end{array}$ & Trial ID Number & $\begin{array}{l}\text { Estimated } \\
\text { Primary } \\
\text { Completion }\end{array}$ \\
\hline ARASENS & $\mathrm{mCSPC}$ & 3 & $\mathrm{ADT}+$ docetaxel + darolutamide or placebo & OS & NCT02799602 & August 2022 \\
\hline EORTC-1532 & CSPC & 2 & ADT vs darolutamide & PSA response & NCT02972060 & December 2020 \\
\hline SGCCR & $\mathrm{mCRPC}$ & 2 & Post-docetaxel maintenance darolutamide vs placebo & RPFS & NCT0293380I & December 2020 \\
\hline ODENZA & mCRPC & 2 & Enzalutamide vs darolutamide & Patient preference & NCT033|4324 & January 2022 \\
\hline INTREPId & Localized & 2 & $\mathrm{RT}+\mathrm{ADT}+$ bicalutamide vs $\mathrm{RT}=$ darolutamide & PSA nadir $\leq 0.5$ & NCT04025372 & September 2022 \\
\hline
\end{tabular}

hypertension (all-grade RR 1.79, high-grade 2.19) with abiraterone. $^{55}$

In Phase 3 studies of the third-generation nonsteroidal antiandrogens, major adverse cardiovascular events (MACE) were fairly uncommon. The rate for enzalutamide was $5 \%$ vs $3 \%$ for placebo in ARAMIS, and investigators reported small incidences of cerebral ischemia, coronary artery disorder, and heart failure, though rates were similar to placebo (Table 5). MACE were not reported in apalutamide Phase 3.

\section{Drug Interactions}

Patients with advanced PCa commonly have significant comorbidities and take many concurrent medications. ${ }^{41}$ While enzalutamide and apalutamide strongly induce CYP3A4, darolutamide has shown no clinically relevant inhibition of CYP1A2, 2A6, 2B6, 2C8, 2C9, 2C19, 2D6, $2 \mathrm{E} 1$, or $3 \mathrm{~A} 4 .^{56,57}$ This distinction may explain the lack of significant differences in toxicity between darolutamide and placebo in ARAMIS. ${ }^{41}$

\section{Future Use}

Current clinical recommendation in MOCRPC is that darolutamide be combined with ADT or bilateral orchiectomy. ${ }^{58}$ This strategy dovetails with the trend toward combination therapies designed to attack PCa via multiple mechanisms to overcome resistance ${ }^{15}$ and supports earlier use of potent AR signaling inhibitors in patients with MOCRPC. ${ }^{1,59}$ Additional settings in which darolutamide is being explored include localized and castration-sensitive PCa (Table 6), in combined and head-to-head regimens.

Potential obstacles for darolutamide include the possibility that, as the third drug approved for MOCRPC, it may have difficulty gaining market share. ${ }^{41}$ On a more specific note, the ARASENS trial in combination with ADT and docetaxel has not yet reported results.

\section{Conclusion}

In an era of increasingly precise, personalized medicine that now includes multiple efficacious options for M0CRPC, treatment decisions for these patients likely will rest largely on safety, cost, drug availability, and patient preferences. Along with significant therapeutic benefit, darolutamide appears to provide safety and QOL comparable to other third-generation ARIs. Ongoing research will further characterize its place among treatments for nonmetastatic CRPC, and perhaps other PCa types. With a limited number of darolutamide studies presently available, efficacy and safety data are based largely on clinical trials. As with any fairly recently approved drug, postmarketing data are expected to highlight delayed and rare AEs.

\section{Acknowledgments}

This activity is supported by an independent medical education grant from Bayer for medical writing of this manuscript. The authors acknowledge the contributions of medical writer John Jesitus in helping to prepare this manuscript. 


\section{Disclosure}

Dr Crawford is a consultant, advisor, meeting participant, and lecturer for Bayer; a consultant or advisor for Dendreon, Ferring, Genomic Health, Janssen, MDxHealth, and Tolmar; a meeting participant or lecturer for Astellas and Pfizer; and a clinical investigator for the University of Colorado Cancer Center and the National Institutes of Health. Dr Mandair and Ms Stanton report no relevant financial interests.

\section{References}

1. Fizazi K, Shore N, Tammela TL, et al. Darolutamide in nonmetastatic, castration-resistant prostate cancer. N Engl J Med. 2019;380 (13):1235-1246. doi:10.1056/NEJMoa1815671

2. American Cancer Society. Cancer Facts \& Figures 2020. Atlanta: American Cancer Society; 2020. Available from https://www.cancer. $\mathrm{org} /$ content $/$ dam/cancer-org/research/cancer-facts-and-statistics /annual-cancer-facts-and-figures/2020/cancer-facts-and-figures-2020. pdf.Accessed January 27, 2020.

3. National Comprehensive Cancer Network. NCCN clinical practice guidelines in oncology: prostate cancer version 1.2020. Available from: https://www.nccn.org/professionals/physician_gls/pdf/prostate. pdf. Accessed May 20, 2020.

4. Mottet N, van den Bergh RCN, Briars E, et al. Prostate cancer guidelines 2019. Available from: https://uroweb.org/guideline/pros tate-cancer/. Accessed January 27, 2020.

5. Cornford P, Bellmunt J, Bolla $\mathrm{M}$, et al. EAU-ESTRO-SIOG Guidelines on Prostate Cancer. Part II: treatment of Relapsing, Metastatic, and Castration-Resistant Prostate Cancer. Eur Urol. 2017;71(4):630-642. doi:10.1016/j.eururo.2016.08.002

6. Gründker C, Emons G. The role of gonadotropin-releasing hormone in cancer cell proliferation and metastasis. Front Endocrinol. 2017;8:187. doi:10.3389/fendo.2017.00187

7. Lowrance WT, Murad MH, Oh WK, Jarrard DF, Resnick MJ, Cookson MS. Castration-resistant prostate cancer: AUA guideline amendment 2018. J Urol. 2018;200(6):1264-1272. doi:10.1016/j. juro.2018.07.090

8. Karantanos T, Evans C, Tombal B, Thompson TC, Montironi R, Isaacs WB. Understanding the mechanisms of androgen deprivation resistance in prostate cancer at the molecular level. Eur Urol. 2015;67(3):470-479. doi:10.1016/j.eururo.2014.09.049

9. Gravis G, Boher J-M, Joly F, et al. Androgen deprivation therapy (ADT) plus docetaxel versus ADT alone in metastatic non-castrate prostate cancer: impact of metastatic burden and long-term survival analysis of the randomized phase 3 GETUG-AFU15 trial. Eur Urol. 2016;70(2):256-262. doi:10.1016/j.eururo.2015.11.005

10. Crawford ED, Schellhammer PF, McLeod DG, et al. Androgen receptor-targeted treatments of prostate cancer: 35 years of progress with antiandrogens. J Urol. 2018;200(5):956-966. doi:10.1016/j. juro.2018.04.083

11. Scher HI, Halabi S, Tannock I, et al. Design and end points of clinical trials for patients with progressive prostate cancer and castrate levels of testosterone: recommendations of the Prostate Cancer Clinical Trials Working Group. J Clin Oncol. 2008;26(7):1148-1159. doi:10.1200/JCO.2007.12.4487

12. Hess-Busch Y, Hadaschik B, Hess J. M0CRPC overview of management options. World J Urol. 2019:5.

13. Fizazi K, Smith MR, Tombal B. Clinical development of darolutamide: a novel androgen receptor antagonist for the treatment of prostate cancer. Clin Genitourin Cancer. 2018;16(5):332-340. doi:10.1016/j.clgc.2018.07.017
14. McCarthy M, Francis R, Tang C, Watts J, Campbell A. A multicenter prospective clinical trial of ${ }^{68}$ Gallium PSMA HBED-CC PET-CT restaging in biochemically relapsed prostate carcinoma: oligometastatic rate and distribution compared with standard imaging. Int J Radiat Oncol Biol Phys. 2019;104(4):801-808. doi:10.1016/j. ijrobp.2019.03.014

15. Rice MA, Malhotra SV, Stoyanova T. Second-generation antiandrogens: from discovery to standard of care in castration resistant prostate cancer. Front Oncol. 2019;9:801. doi:10.3389/fonc. 2019.00801

16. El-Amm J, Aragon-Ching JB. The current landscape of treatments in nonmetastatic castration-resistant prostate cancer. Clin Med Insights Oncol. 2019;13. Available from https://journals.sagepub.com/doi/pdf/ 10.1177/1179554919833927. Accessed, 2020.

17. Zhou ZX, Lane MV, Kemppainen JA, French FS, Wilson EM. Specificity of ligand-dependent androgen receptor stabilization: receptor domain interactions influence ligand dissociation and receptor stability. Mol Endocrinol. 1995;9(2):208-218. doi:10.1210/ mend.9.2.7776971

18. Wright AS, Douglas RC, Thomas LN, Lazier CB, Rittmaster RS. Androgen-induced regrowth in the castrated rat ventral prostate: role of 5alpha-reductase. Endocrinology. 1999;140(10):4509-4515. doi:10.1210/endo.140.10.7039

19. Scher HI, Sawyers CL. Biology of progressive, castration-resistant prostate cancer: directed therapies targeting the androgen-receptor signaling axis. J Clin Oncol. 2005;23(32):8253-8261. doi:10.1200/ JCO.2005.03.4777

20. Andriole GL, Crawford ED, Grubb RL, et al. Mortality results from a randomized prostate-cancer screening trial. $N$ Engl $J$ Med. 2009;360(13):1310-1319. doi:10.1056/NEJMoa0810696

21. Goldenberg SL, Bruchovsky N. Use of cyproterone acetate in prostate cancer. Urol Clin North Am. 1991;18(1):111-122.

22. Group PCTC. Prostate Cancer Trialists' Collaborative Group. Maximum androgen blockade in advanced prostate cancer: an overview of the randomised trials. Lancet. 2000;355(9214):1491-1498. doi:10.1016/S0140-6736(00)02163-2

23. Thorpe SC, Azmatullah S, Fellows GJ, Gingell JC, O'Boyle PJ. A prospective, randomised study to compare goserelin acetate (Zoladex) versus cyproterone acetate (Cyprostat) versus a combination of the two in the treatment of metastatic prostatic carcinoma. Eur Urol. 1996;29(1):47-54. doi:10.1159/000473717

24. Saranyutanon S, Srivastava SK, Pai S, Singh S, Singh AP. Therapies targeted to androgen receptor signaling axis in prostate cancer: progress, challenges, and hope. Cancers. 2019;12(1):51. doi:10.3390/ cancers 12010051

25. Plante M, Lapointe S, Labrie F. Stimulatory effect of synthetic progestins currently used for the treatment of prostate cancer on growth of the androgen-sensitive Shionogi tumor in mice. J Steroid Biochem. 1988;31(1):61-64. doi:10.1016/0022-4731(88)90206-3

26. Labrie F, Luthy I, Veilleux R, Simard J, Bélanger A, Dupont A. New concepts on the androgen sensitivity of prostate cancer. Prog Clin Biol Res. 1987;243A:145-172.

27. Knudsen KE, Kelly WK. Outsmarting androgen receptor: creative approaches for targeting aberrant androgen signaling in advanced prostate cancer. Expert Rev Endocrinol Metab. 2011;6(3):483-493. doi:10.1586/eem.11.33

28. Culig Z, Hoffmann J, Erdel M, et al. Switch from antagonist to agonist of the androgen receptor bicalutamide is associated with prostate tumour progression in a new model system. Br J Cancer. 1999;81(2):242-251. doi:10.1038/sj.bjc.6690684

29. Hara T, Miyazaki J, Araki H, et al. Novel mutations of androgen receptor: a possible mechanism of bicalutamide withdrawal syndrome. Cancer Res. 2003;63(1):149-153.

30. Tran C, Ouk S, Clegg NJ, et al. Development of a second-generation antiandrogen for treatment of advanced prostate cancer. Science. 2009;324(5928):787-790. doi:10.1126/science. 1168175 
31. Hussain M, Fizazi K, Saad F, et al. Enzalutamide in men with nonmetastatic, castration-resistant prostate cancer. $N$ Engl J Med. 2018;378(26):2465-2474. doi:10.1056/NEJMoa1800536

32. Smith MR, Saad F, Chowdhury S, et al. Apalutamide treatment and metastasis-free survival in prostate cancer. $N$ Engl J Med. 2018;378 (15):1408-1418. doi:10.1056/NEJMoa1715546

33. Moilanen AM, Riikonen R, Oksala R, et al. Discovery of ODM-201, a new-generation androgen receptor inhibitor targeting resistance mechanisms to androgen signaling-directed prostate cancer therapies. Sci Rep. 2015;5(1):12007. doi:10.1038/srep12007

34. Fizazi K, Albiges L, Loriot Y, Massard C. ODM-201: a new-generation androgen receptor inhibitor in castration-resistant prostate cancer. Expert Rev Anticancer Ther. 2015;15(9):1007-1017. doi:10.1586/ 14737140.2015 .1081566

35. Zurth C, Sandmann S, Trummel D, Seidel D, Gieschen H. Bloodbrain barrier penetration of [14C]darolutamide compared with [14C]enzalutamide in rats using whole body autoradiography. J Clin Oncol. 2018;36(6_suppl):345. doi:10.1200/JCO.2018.36. 6_suppl.345

36. Zurth C, Sandmann S, Trummel D, Seidel D, Nubbemeyer R, Gieschen H. Higher blood-brain barrier penetration of [14C]apalutamide and [14C]enzalutamide compared to [14C]darolutamide in rats using whole-body autoradiography. J Clin Oncol. 2019;37 (7_suppl):156. doi:10.1200/JCO.2019.37.7_suppl.156

37. Fizazi K, Massard C, Bono P, et al. Safety and antitumour activity of ODM-201 (BAY-1841788) in castration-resistant, CYP17 inhibitornaïve prostate cancer: results from extended follow-up of the ARADES trial. Eur Urol Focus. 2017;3(6):606-614. doi:10.1016/j. euf.2017.01.010

38. Massard C, Tammela TLJ, Vjaters E, et al. A study of two ODM-201 formulations with a safety and tolerability extension phase in patients with metastatic chemotherapy-naive castration-resistant prostate cancer (CRPC). J Clin Oncol. 2014;32(4_suppl):115. doi:10.1200/ jco.2014.32.4_suppl.115

39. Massard C, Penttinen HM, Vjaters E, et al. Pharmacokinetics, antitumor activity, and safety of ODM-201 in patients with chemotherapy-naive metastatic castration-resistant prostate cancer: an open-label Phase 1 study. Eur Urol. 2016;69(5):834-840. doi:10.1016/j.eururo.2015.09.046

40. Fizazi K, Shore ND, Tammela T, et al. Overall survival (OS) results of phase III ARAMIS study of darolutamide (DARO) added to androgen deprivation therapy (ADT) for nonmetastatic castrationresistant prostate cancer (nmCRPC). J Clin Oncol. 2020;38(15): (suppl; abstr 5514). doi:10.1200/JCO.2020.38.15_suppl.5514. Published online May 25, 2020

41. Bastos DA, Antonarakis ES. Darolutamide for castration-resistant prostate cancer. OncoTargets Ther. 2019;12:8769-8777. doi:10.21 47/OTT.S197244

42. Basch E, Autio K, Ryan CJ, et al. Abiraterone acetate plus prednisone versus prednisone alone in chemotherapy-naive men with metastatic castration-resistant prostate cancer: patient-reported outcome results of a randomised phase 3 trial. Lancet Oncol. 2013;14(12):1193-1199. doi:10.1016/S1470-2045(13)70424-8

43. Sternberg CN, Molina A, North S, et al. Effect of abiraterone acetate on fatigue in patients with metastatic castration-resistant prostate cancer after docetaxel chemotherapy. Ann Oncol. 2013;24 (4):1017-1025. doi:10.1093/annonc/mds585

44. Scher HI, Beer TM, Higano CS, et al. Antitumour activity of MDV3100 in castration-resistant prostate cancer: a phase 1-2 study. Lancet. 2010;375(9724):1437-1446. doi:10.1016/S0140-6736(10) 60172-9
45. Shore ND, Tammela TL, Massard C, et al. Safety and antitumour activity of ODM-201 (BAY-1841788) in chemotherapy-naïve and CYP17 inhibitor-naïve patients: follow-up from the ARADES and ARAFOR trials. Eur Urol Focus. 2018;4(4):547-553. doi:10.1016/j. euf.2017.01.015

46. Roviello G, Gatta Michelet MR, D’Angelo A, Nobili S, Mini E. Role of novel hormonal therapies in the management of non-metastatic castration-resistant prostate cancer: a literature-based meta-analysis of randomized trials. Clin Transl Oncol. 2019.

47. Di Nunno V, Mollica V, Santoni M, et al. New hormonal agents in patients with nonmetastatic castration-resistant prostate cancer: meta-analysis of efficacy and safety outcomes. Clin Genitourin Cancer. 2019;17(5):e871-e877. doi:10.1016/j.clgc.2019.07.001

48. U.S. Food and Drug Administration. FDA drug safety communication: update to ongoing safety review of GnRH agonists and notification to manufacturers of GnRH agonists to add new safety information to labeling regarding increased risk of diabetes and certain cardiovascular diseases. FDA. June 2019. Available from: http://www.fda.gov/drugs/drug-safety-and-availability/fda-drugsafety-communication-update-ongoing-safety-review-gnrh-agonistsand-notification. Accessed January 29, 2020.

49. O'Farrell S, Garmo H, Holmberg L, Adolfsson J, Stattin P, Van Hemelrijck M. Risk and timing of cardiovascular disease after androgen-deprivation therapy in men with prostate cancer. $J$ Clin Oncol. 2015;33(11):1243-1251. doi:10.1200/JCO.2014.59.1792

50. Potter GA, Barrie SE, Jarman M, Rowlands MG. Novel steroidal inhibitors of human cytochrome P45017 alpha (17 alpha-hydroxylase-C17,20-lyase): potential agents for the treatment of prostatic cancer. $J$ Med Chem. 1995;38(13):2463-2471. doi:10.1021/jm00013a022

51. Attard G, Belldegrun AS, de Bono JS. Selective blockade of androgenic steroid synthesis by novel lyase inhibitors as a therapeutic strategy for treating metastatic prostate cancer. BJU Int. 2005;96 (9):1241-1246. doi:10.1111/j.1464-410X.2005.05821.x

52. Ryan CJ, Crawford ED, Shore ND, et al. The IMAAGEN study: effect of abiraterone acetate and prednisone on prostate specific antigen and radiographic disease progression in patients with nonmetastatic castration resistant prostate cancer. J Urol. 2018;200 (2):344-352. doi:10.1016/j.juro.2018.03.125

53. Ryan CJ, Smith MR, de Bono JS, et al. Abiraterone in metastatic prostate cancer without previous chemotherapy. $N$ Engl J Med. 2013;368(2):138-148. doi:10.1056/NEJMoa1209096

54. de Bono JS, Logothetis CJ, Molina A, et al. Abiraterone and increased survival in metastatic prostate cancer. $N$ Engl J Med. 2011;364(21):1995-2005. doi:10.1056/NEJMoa1014618

55. Iacovelli R, Ciccarese C, Bria E, et al. The cardiovascular toxicity of abiraterone and enzalutimide in prostate cancer. Clin Genitourin Cancer. 2018;16(3):e645-e653. doi:10.1016/j.clgc.2017.12.007

56. Zurth C, Koskinen M, Fricke R, et al. Drug-drug interaction potential of darolutamide: in vitro and clinical studies. Eur J Drug Metab Pharmacokinet. 2019;44(6):747-759. doi:10.1007/s13318-019-00577-5

57. Shore N, Zurth C, Fricke R, et al. Evaluation of clinically relevant drug-drug interactions and population pharmacokinetics of darolutamide in patients with nonmetastatic castration-resistant prostate cancer: results of pre-specified and post hoc analyses of the Phase III ARAMIS trial. Target Oncol. 2019;14(5):527-539. doi:10.1007/ s11523-019-00674-0

58. Nubeqa ${ }^{\circledR}$ (Darolutamide) [Prescribing Information]. Whippany, NJ: Bayer HealthCare Pharmaceuticals, Inc; 2019.

59. Mateo J, Fizazi K, Gillessen S, et al. Managing nonmetastatic castration-resistant prostate cancer. Eur Urol. 2019;75(2):285-293. doi:10.1016/j.eururo.2018.07.035 


\section{Publish your work in this journal}

Cancer Management and Research is an international, peer-reviewed open access journal focusing on cancer research and the optimal use of preventative and integrated treatment interventions to achieve improved outcomes, enhanced survival and quality of life for the cancer patient.

The manuscript management system is completely online and includes a very quick and fair peer-review system, which is all easy to use. Visit http://www.dovepress.com/testimonials.php to read real quotes from published authors.

Submit your manuscript here: https://www.dovepress.com/cancer-management-and-research-journal 